\title{
Estudo Da Viabilidade Técnica De Um Sistema Automatizado Para Inclusão Do Deficiente Visual Na Indústria: Adaptação Do Deficiente Visual Em Uma Célula Produtiva
}

\author{
Study The Technical Feasibility Of An Automated System For \\ Inclusion Of Visually Deficient In The Industry: Adaptation Of The \\ Visually Deficient In A Production Cell
}

Sebastião Garcia Junior¹, Luciano Galdino² e João Carlos Lopes Fernandes³

\begin{abstract}
1. Professor de Mecânica Básica e Processos Industriais na faculdade ENIAC. Sócio Diretor da A\&S Automação Industrial. Bacharel em Engenharia Mecatrônica pela faculdade ENIAC e Tecnólogo em Mecatrônica Industrial pela faculdade de Tecnologia ENIAC-FAPI. 2. Professor de Física e Elementos de Máquina na Faculdade ENIAC. Mestre em Ciências Exatas e da Terra na área de Física Nuclear pela USP, especializado em Física pela USP e Licenciado em Matemática pela UNG. E-mail: lucianogaldino1@yahoo.com.br.

3. Professor pesquisador na Faculdade ENIAC. Doutor em engenharia biomédica pela UMC, Mestre em engenharia de computação pelo IPT/USP. Licenciado em ciências da computação pela USCS. E-mail: joao.carlos@eniac.com.br.
\end{abstract}

\section{Resumo}

Atualmente na sociedade existe a necessidade de que sejam implantadas ferramentas de inclusão social para deficientes em geral, e nas indústrias isso não é diferente. No caso específico do deficiente visual, até o momento, não há qualquer tipo de ferramenta ou sistema que possibilite a inclusão deste em um ambiente produtivo e nem sequer normas específicas para assegurar a sua integridade física. Baseado nisto, este artigo apresenta o desenvolvimento de um sistema automático que possibilite a substituição do sentido da visão pelo tato, possibilitando o trabalho de um deficiente visual em um ambiente produtivo industrial, através de componentes comuns utilizados em automação industrial, apoiado em normas de segurança gerais já existentes. Será abordada também a análise da viabilidade técnica para implantação e um exemplo de um setor industrial para deficientes visuais.

Palavras chave: Deficiente visual. Inclusão. Indústria.

\begin{abstract}
Currently there is a need in society that are deployed tools of social inclusion for deficient in general, and in the industries, it is no different. In the specific case of the visually deficient, to date, there is no type of tool or system that enables the inclusion of this in a production environment and not even specific standards to ensure their physical integrity. Based on this this paper presents the development of an automated system that allows the replacement of the sense of sight by touch, allowing the work of a visually deficient in an industrial production environment through common components used in industrial automation supported by safety standards existing general. Will also be addressed to analyze the technical feasibility for implementation and an example of an industrial sector for the visually deficient.
\end{abstract}

Keys-words: Visually deficient. Inclusion. Industry. 


\section{Introdução}

As pessoas portadoras de deficiência têm os mesmos direitos fundamentais que as outras pessoas, dentre eles o direito de não ser submetidas à discriminação por ser portador de deficiencia, pois emanam da dignidade e da igualdade que são inerentes a todo ser humano.

Atualmente, com o crescimento da população, também aumenta o número de deficientes visuais. $\mathrm{O}$ portador desta deficiência vem alcançando a cada dia um espaço no mercado de trabalho graças ao crescente avanço tecnológico voltado ao apoio desse tipo de deficiência. Hoje já existem inúmeros produtos os quais são especialmente desenvolvidos para este público, produtos que auxiliam a se locomover, a comprar e até a ler livros. Com o objetivo de incluir este portador de deficiência no mercado consumidor, muitas empresas adequaram seus produtos na escrita braile.

O objetivo desse artigo é apresentar um sistema que integra uma botoeira a um Controlador Lógico Programável (CLP) onde a mesma irá efetuar, digitalmente, funções que facilmente serão interpretadas somente com o tato e a audição, isto é, enviará informações que suprirão a falta do sentido da visão. Este dispositivo vai se comunicar com a máquina e emitir sinais sonoros e de vibração de tal forma que seja possível ao deficiente visual identificar todas as operações do processo a que estará sendo executado na máquina e/ou processo, de forma rápida e segura.

Será apresentado o quadro geral dos deficientes físicos no Brasil (focando-se nos deficientes visuais), os dispositivos de segurança propostos como cortina de luz, sensores, comando bi manual, chave de segurança, controlador lógico programável (CLP) e botão de emergência tipo "soco", as normas gerais de segurança existentes e o problema da carência de normas específicas para atuação de deficientes visuais em linhas de produção na indústria. Será ressaltado o funcionamento do sistema proposto juntamente com os dados técnicos e uma análise da viabilidade de sua implantação em uma planta industrial, além da dedução da equação que relaciona a rotação com a tensão aplicada.

\section{Deficiências No Brasil}

Os resultados obtidos no Censo 2010 indicaram que o número de pessoas com deficiência chega a aproximadamente 45,6 milhões que segundo o IBGE (2010) representava na época $23,9 \%$ da população brasileira. Essas deficiências estão relacionadas à deficiência física ou mental, enquadrando-se também pessoas com dificuldades de enxergar, ouvir ou locomover-se, não necessariamente sendo cegas, surdas, paraplégicas ou tetraplégicas. Já em 2000, o Censo indicou 24,5 milhões de pessoas com deficiência o que 
representava na época $14,5 \%$ da população brasileira, isto é, tanto o número de pessoas como a porcentagem da população com deficiência aumentou significativamente.

É importante destacar que a proporção de pessoas portadoras de deficiência aumenta com a idade, passando de 4,3\% nas crianças até 14 anos, para $54 \%$ do total das pessoas com idade superior a 65 anos. À medida que a estrutura da população está mais envelhecida, a proporção de pessoas com deficiência aumenta, surgindo um novo elenco de demandas para atender as necessidades específicas deste grupo.

Os dados do Censo 2010 mostram, também, que os homens predominam no caso de deficiência mental, física (especialmente no caso de falta de membro ou parte dele) e auditiva. O resultado é compatível com o tipo de atividade desenvolvida pelos homens e com o risco de acidentes de diversas causas. Já a predominância das mulheres com dificuldades motoras (incapacidade de caminhar ou subir escadas) ou visuais está relacionada com a população idosa, com o predomínio de mulheres a partir dos 60 anos.

Em relação à instrução, as diferenças são marcantes: $32,9 \%$ da população sem instrução ou com menos de três anos de estudo é portadora de deficiência. As proporções de portadores de deficiência caem quando aumenta o nível de instrução, chegando a 10\% de portadores de deficiência entre as pessoas com mais de 11 anos de estudo.

A proporção de pessoas ocupadas é de $51,8 \%$ para os homens portadores de deficiência e de 63,0\% para os homens que declararam não possuir nenhuma das deficiências investigadas, ou seja, uma diferença maior que 10\%. Diferença semelhante é observada entre as mulheres: a proporção de ocupadas varia entre $27 \%$ e $37 \%$. O tipo de deficiência que dificulta mais a inserção no mercado de trabalho é a deficiência mental: somente $19,3 \%$ das pessoas que declararam apresentar deficiência mental permanente estão ocupadas. As outras incapacidades permitem uma inserção maior no mercado de trabalho: incapacidade física ou motora $(24,1 \%)$, dificuldade na audição $(34,0 \%)$ e dificuldade para enxergar (40,8\%). Para quem não apresenta nenhuma destas deficiências, a proporção de pessoas ocupadas sobe para 49,9\%.

A Lei de Cotas ( $n^{\circ}$ 8.213/91) obriga as empresas a reservar uma parcela de suas vagas para a inclusão de pessoas com deficiência. A lei exige que $2 \%$ das vagas sejam reservadas para pessoas com deficiência em estabelecimentos comerciais que tenham de 100 a 200 funcionários. Para as que têm de 201 a 500 empregados, a cota é de 3\% e, para as que têm de 501 a mil cooperados, de 4\%. Acima disso, as companhias não devem ter menos de $5 \%$ de inclusões. Seu descumprimento pode resultar em multas.

\subsection{Deficiência Visual}

Segundo o IBGE (2010), 35,7 milhões de pessoas apresentam algum grau de deficiência visual, entre elas, mais de 6,5 milhões apontaram 
muita dificuldade em enxergar e mais de 506 mil declararam serem cegas.

Os sentidos têm as mesmas características de potencialidades para todas as pessoas. As informações tátil, auditiva, sinestésica e olfativa são mais desenvolvidas pelas pessoas cegas porque elas recorrem a esses sentidos com mais frequência para decodificar $e$ guardar na memória as informações. Sem a visão, os outros sentidos passam a receber a informação de forma intermitente, fugidia e fragmentária. O sistema hepático é o tato ativo, constituído por componentes cutâneos e sinestésicos, através dos quais impressões, sensações e vibrações detectadas pelo individuo são interpretadas pelo cérebro e constituem fontes valiosas de informação. Uma demonstração surpreendente da capacidade de coleta e do processamento de informações pela via do tato é o tadoma, mecanismo de comunicaşão utilizado por pessoas surdocegas. Trata-se de uma comunicação eminentemente tátil que permite entender a fala de uma pessoa, ao perceber as vibraçoes e os movimentos articulatórios dos lábios e maxilares com a mão sobre a face do interlocutor. (SÁ, CAMPOS E SILVA, 2007 p. 15-16).

Kastrup (2008) salienta que muito se tem destacado sobre a relevância funcional do tato na vida prática e cotidiana das pessoas cegas. O tato é considerado o sentido mais apropriado para fornecer as referências para deslocamento no espaço, que deixaram de existir com a perda de visão, e é por meio dele que a maior parte do conhecimento espacial deve ser reconstruída.

1 Norma que define as referências técnicas, os princípios fundamentais e medidas de proteção que garantem a saúde e integridade física dos trabalhadores através de definições de protocolos e fluxos de trabalho
A evolução tecnológica muito contribui para a inclusão dos deficientes visuais. Campbell (2001, p.107) aponta que "desde a invenção do Código Braille em 1829, nada teve tanto impacto nos programas de educação, reabilitação e emprego quanto o recente desenvolvimento da informática para os cegos".

Já Gil (2000), aponta que com o desenvolvimento tecnológico, especialmente nas áreas de microeletrônica e informática, surgem novas profissões e empregos para os deficientes visuais, atividades que até pouco tempo eram difíceis de imaginar serem executadas por uma pessoa com essa deficiência.

\section{Dispositivos De Segurança Aplicados \\ No Sistema}

O Artigo 186 da CLT (Consolidação das Leis do Trabalho) e NR12 ${ }^{1}$ em seu item 12.2.2 determinam que as máquinas e os equipamentos com acionamentos repetitivos deverão receber proteção adequada. Segundo a NBR NM 272 (Segurança de Máquinas - Proteções Requisitos gerais para o projeto e Construção de proteções fixas e móveis), proteção é definida como parte da máquina especificamente utilizada para prover proteção por meio de uma barreira física.

em todas as fases de operação e manutenção de máquinas, treinamento documentado de todos os empregados envolvidos, e a projeção e instalação de sistemas de segurança. 
Conforme NBR NM 272:2002 e 273:2002, todas as proteções físicas utilizadas na proteção de máquinas devem conter dispositivos de proteção para monitorar as movimentações na manipulação, liberando o funcionamento da máquina somente se tudo estiver conforme o projeto de segurança ou utilizando chaves de segurança, para assegurar a paralisação imediata da máquina sempre que ocorrer alguma movimentação inadequada.

São vários os dispositivos elétricos de segurança aplicados em mecanismos automatizados, sendo que a seguir serão apresentados apenas os dispositivos aplicados neste projeto e que atendam às normas.

3.1.1. Chaves de Intertravamento de Segurança Operada por Lingueta sem Solenóide.

Weg (2014) explica que a chave de intertravamento de segurança compacta (figura 1) foi projetada para fornecer o monitoramento de proteções móveis pequenas, e esta certificada conforme as normas EN 1088, IEC 60947-5-1, EN 60204-1, ISO 13849-1, EN 62061, EN 9541, UL 508.

Este chave tem por finalidade monitorar a abertura de proteções fixas a fim de manter o grau de segurança necessário para a proteção do deficiente visual através de sua redundância de acionamento nos contatos juntamente com a lingueta de acionamento que deverá ficar fixa em um dos lados das proteções.
Figura 1: Chave de segurança compacta

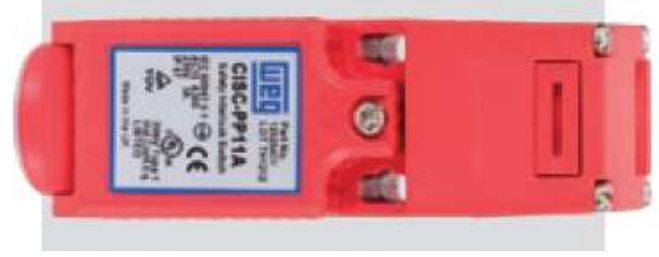

Fonte: Catálogo Weg linha safety

\subsubsection{Dispositivo de parada emergência com monitoramento}

Segundo Weg (2014), este dispositivo de segurança (figura 2) foi desenvolvido de acordo com as normas internacionais IEC 60947-5-5 e UL 508 para atender aos requisitos da norma brasileira NR12. Ele tem por finalidade garantir a condição de parada de emergência do equipamento, além de assegurar a falha física de montagem do mesmo através de um contato de monitoramento, responsável pela verificação se o botão está ou não fixado corretamente no dispositivo.

Figura 2: Botão de emergência com contato monitorado

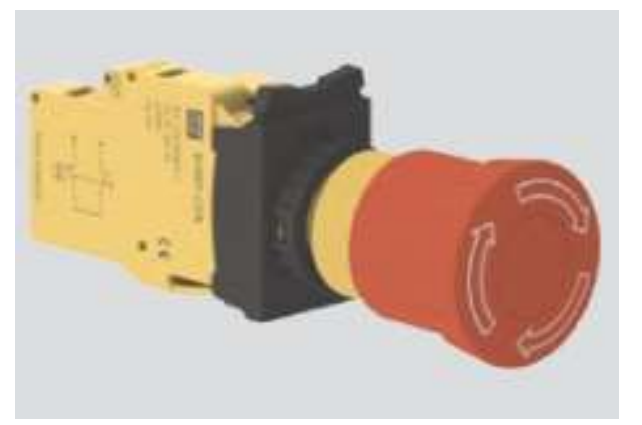

Fonte: Catálogo WEG linha safety

\subsubsection{Sensores magnéticos de segurança}

Os sensores magnéticos de proteção (figura 3) objetivam efetuar o monitoramento de proteções fixas ou móveis garantindo que 
quando houver o rompimento de qualquer uma dessas ocorra a parada imediata do equipamento. Ele possui acionamento de duplo contato através da aproximação de um campo magnético de frente ao sensor. Segundo a Weg (2014), o sensor Magnético da linha safety é homologado pelas normas, IEC 60947-5-1, -5-3; IEC 610006-2; IEC 61000-4-6, 2006/42 (diretiva de máquinas), NBR 14153; IEC 60204; EN ISO 13849-1, PL e1), IEC 62061 SIL31).

Figura 3: Sensores indutivos de segurança

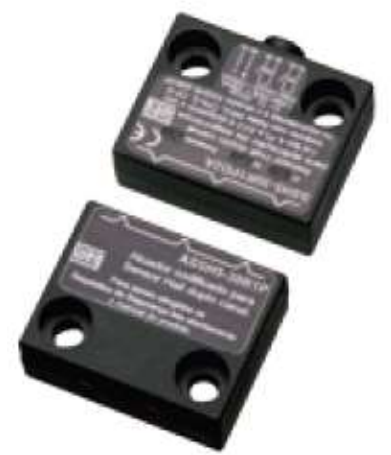

Fonte: Catálogo WEG linha safety

\subsubsection{Comando bi manual}

O comando bi manual (figura 4) é um dispositivo de segurança dotado de acionamento por simultaneidade, a fim de garantir que o operador esteja com as duas mãos longe da área de movimentação das máquinas. Seu funcionamento é homologado pela norma IEC 61000-4-2: 2001 e possui grau de proteção IP20 (WEG, 2014).
Figura 4: Comando bi manual

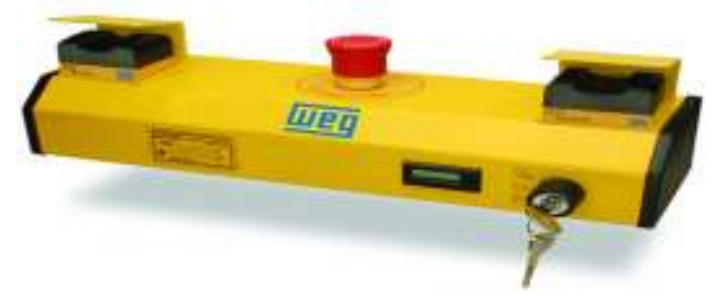

Fonte: Catálogo WEG linha safety

\subsubsection{Cortina de luz}

O sistema cortina de luz (figura 5) consiste de um transmissor, um receptor e um sistema de controle. O campo de atuação dos sensores é formado por múltiplos transmissores e receptores de fachos individuais. É gerado um sinal de falha para cada conjunto de transmissores e receptores ativados caso o receptor não receba o feixe luminoso de infravermelho do transmissor. A cortina de luz deverá ser adequadamente selecionada de acordo com a altura de proteção e a resolução (capacidade de percepção de dedos ou mão), e posicionada a uma distância segura da zona de risco, levando em conta o tempo total de parada da máquina, devendo ainda monitorada por relês ou CLP de segurança.

Figura 5: Cortina de luz

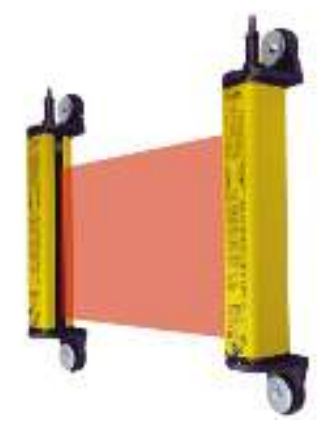

Fonte: Catálogo WEG linha safety. 


\subsubsection{Controlador Lógico Programável (CLP)}

O controlador lógico programável (CLP) é um dispositivo programável muito utilizado na indústria e que atende aos requisitos solicitados de operação. Utiliza um programa específico para o controle e automatização, sendo que frequentemente atua com um sistema operacional em tempo real e a memória com configuração fixa (KOPELVSKI, 2010).

A definição de controlador lógico programável pela Nema (National Electrical Manufacturers Association), ICS3-1978, parte ICS3-04 é:

Aparelho eletrônico digital que utiliza uma memória programável para o armazenamento interno de instruções para implementação de funções especificas, tais como lógica, sequenciamento, temporização, contagem e aritmética para controlar, através de módulos de entradas e saídas, vários tipos de máquinas ou processos.

Segundo Prudente (2010) o Controlador lógico programável (CLP) tem uma enorme diversidade de locais onde pode se aplicar o conceito de processamento dedicado.

\section{Vibrações Mecânicas}

Uma vibração mecânica é denominada como o movimento de uma partícula ou de um corpo que oscila em torno de uma posição de equilíbrio (BEER;JOHNSTON; EISENBERG, 2012).

Conforme (RAO, 2008), em geral, um sistema vibratório inclui um meio para armazenar energia potencial (corpos com propriedades elásticas), um meio para aplicar energia cinética (massa ou inércia) e um meio de perda gradual de energia (amortecedor).

Um motor desbalanceado devido à ação de uma massa acoplada ao seu eixo (figura 6) possui a capacidade de produzir um determinado grau de vibração denominado de vibração forçada. Quando os efeitos de atrito podem ser desprezados, as vibrações são ditas como vibrações não amortecidas (BEER; JOHNSTON; EISENBERG, 2012).

Figura 6: motor desbalanceado devido a aplicação de uma massa

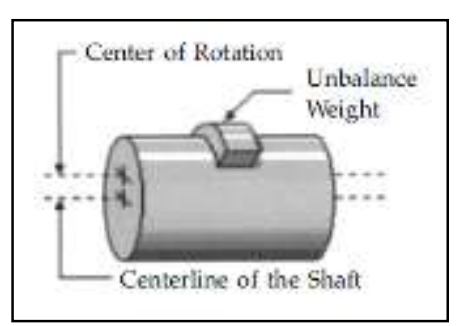

Fonte: Mcmillan (2004)

Já Mcmillan (2004) aponta que qualquer tipo de carga que esteja acoplado ao eixo do motor, produz um desbalanceamento estático que gera uma vibração no sistema.

Normalmente os elementos rotativos tendem a girar em torno do seu próprio centro de gravidade. Em um elemento de máquina, o centro de rotação e o centro de gravidade deveriam ser o mesmo. Caso contrário, devido ao desbalanceamento, resultará em vibração. Desequilíbrio estático é definido como um desequilíbrio em que o centro de rotação se desloca paralelamente para o centro geométrico do elemento rotativo. Se o elemento for colocado em nivel irá girar até que o ponto pesado desloque para parte inferior. (MCMILLAN, 2004). 
Rao (2008) define que a vibração forçada é resultado de um sistema sujeito a uma força externa periódica e Beer, Johnston e Eisenberg (2012) aponta que a amplitude de um sistema (deslocamento máximo em relação ao seu ponto de equilíbrio) se refere à intensidade da vibração, ou seja, a força que a mesma irá exercer sobre determinado sistema, sendo ela uma referência fundamental para análise do comportamento de sistemas vibratórios.

A força resultante do desbalanceamento gerada pela massa excêntrica acoplada ao eixo do motor é a resultante centrífuga a que essa massa está submetida (equação 01).

$$
F=m \cdot \omega^{2} r
$$

Sendo:

$\mathrm{F}=$ Resultante centrífuga.

$\mathrm{m}=$ massa desbalanceada.

$\omega=$ Velocidade angular.

$r=$ Raio entre o eixo e o centro de massa.

A rotação do motor pode ter uma relação direta com a tensão aplicada. O eixo do motor necessita de uma força para gerar um torque e consequentemente iniciar seu ciclo de rotação. Este torque é gerado por forças magnéticas desenvolvidas entre os polos magnéticos do rotor e aqueles do estator ou imã permanente. Forças de atração ou de repulsão produzem torques que fazem o motor girar vencendo o atrito e superando cargas que podem estar acopladas em seu eixo, e assim mantém uma velocidade constante. A potência elétrica útil do motor é transformada em potência mecânica para que seja realizado um trabalho. A potência útil de um motor elétrico é sempre menor que o equivalente mecânico da corrente elétrica aplicada ao motor devido ao atrito, enrolamentos e perdas elétricas (FITZGERALD; KINGSLEY; UMANS, 2006).

Hibbeler (2011) define a potência como trabalho realizado ou a energia transferida por unidade de tempo (equação 02). A unidade de potência no sistema internacional de unidades de medida (SI) é o watt (W), igual a um joule por segundo.

$$
P=\frac{\tau}{\Delta t}
$$

Onde:

$\mathrm{P}=$ Potência em watts $(\mathrm{W})$

$\Delta \mathrm{t}=\mathrm{O}$ tempo em segundos (s)

$\tau=\mathrm{O}$ trabalho realizado ou energia transferida $(\mathrm{J})$

Trabalho é o produto da força (F) pelo deslocamento (s), conforme equação 03. A unidade de trabalho (no SI) é o joule (J), igual a $1 \mathrm{Nm}$. Define-se um joule como a energia transferida ou trabalho realizado por uma força de 1 Newton quando o ponto em que ela é 
aplicada se desloca 1 metro em direção a esta força (BIRD, 2009).

$$
\tau=F . S
$$

Assim, substituindo a equação 03 na equação 02 , obtém-se a equação 04 :

$$
P=\frac{F . s}{\Delta t}
$$

Como se pode analisar na equação (04), a relação entre deslocamento $(s)$, e o tempo $(t)$ é a velocidade periférica (v), assim pode-se descrever a potência conforme a equação (05).

$$
P=F v
$$

Segundo Melconian (2008), a velocidade tangencial ou periférica tem como característica a mudança de trajetória a cada instante, porém o seu módulo permanece constante. A relação entre a velocidade tangencial (v), e a velocidade angular ( $\omega)$, é definida pelo raio (equação 6).

$$
r=\frac{v}{\omega}
$$

Rearranjando a equação (06), obtém-se a equação (07):

$$
v=r \omega
$$

Substituindo a equação (07) na equação (05), chega-se na equação 08:

$$
P=F r \omega
$$

Substituindo a equação 01 na equação 08 , encontra-se a equação 09 que nada mais é do que outra maneira de se calcular a potência.

$$
P=m r^{2} \omega^{3}
$$

Em se tratando de um motor elétrico, a potência pode ser descrita pelo produto da tensão de entrada $(\mathrm{U})$ pela corrente do motor (i), assim chega-se a equação (10).

$$
U i=m r^{2} \omega^{3}
$$

Então, isolando a velocidade angular, chega-se à equação que relaciona a tensão com essa velocidade angular do motor (equação 11):

$$
\omega=\sqrt{\frac{U i}{m r^{2}}}
$$

Como a velocidade angular é em função da rotação (n) dada por $\omega=\frac{\pi n}{30}$, então, chega-se a equação 12 , que relaciona a rotação em função da tensão elétrica aplicada num motor desbalanceado, isto é, alterando a tensão ou a corrente, é possível alterar a rotação e, como o motor é desbalanceado, altera-se também a amplitude da vibração.

$$
n=\frac{30}{\pi} \sqrt{\frac{U i}{m r^{2}}}
$$

\section{Funcionamento Do Sistema}

O funcionamento deste sistema se dará no principio da vibração e sinalização sonora, para poder orientar o deficiente visual quando o processo estiver sendo executado. Um dos sentidos mais potencializado do deficiente visual é o tato, assim, foi projetado um mecanismo que funcione de forma integrada à máquina através de dispositivos elétricos, eletrônicos e 
eletromecânicos, todos estes integrados em uma botoeira com acionamento bi manual. A máquina será dotada de proteção tipo barreira de luz, onde isentará a possibilidade de inserção de partes do corpo em áreas de risco.
Todos os botões estarão com sua identificação feita em chapa de aço prensada com as inscrições em Braille (figura 07) e em uma posição ergonômica correta e segura.

Figura 07: Botoeira de interface com escritas em Braille para o deficiente visual.

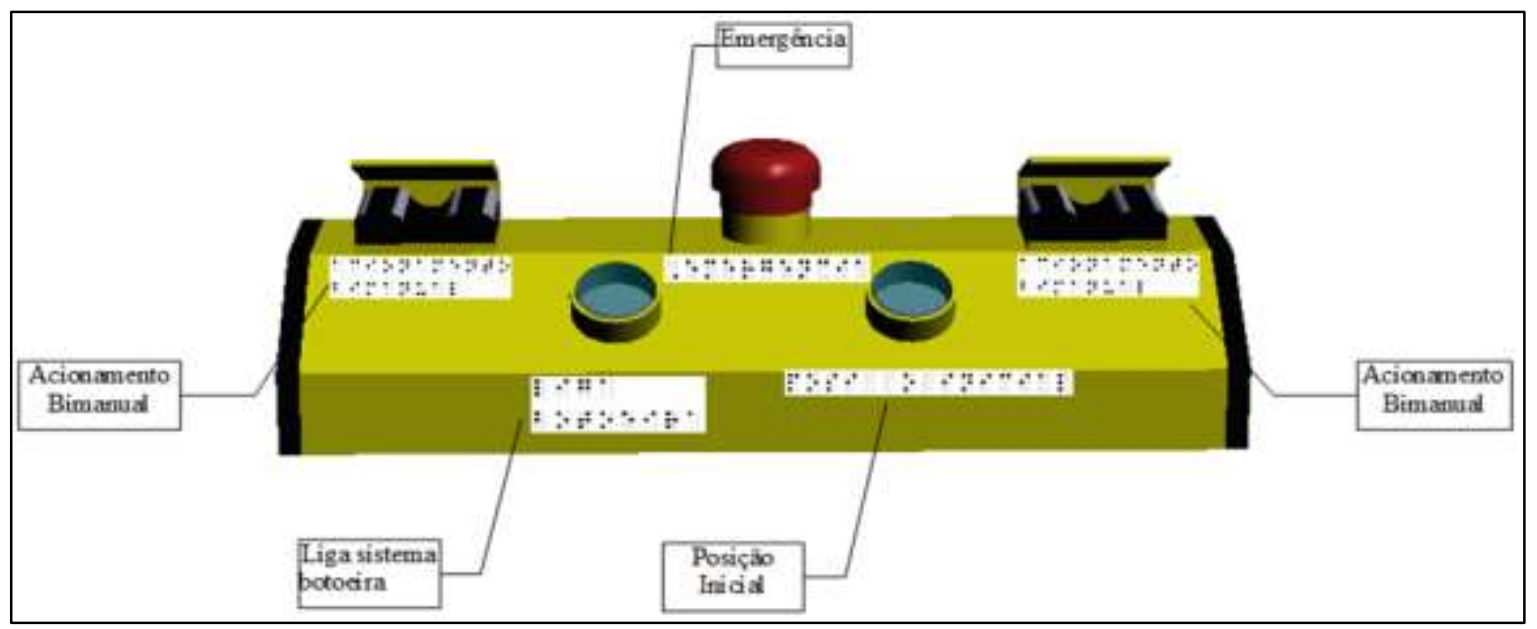

Fonte: Elaborado pelo autor.

Cada botão terá uma função específica, sendo que o quadro 1 apresenta as descrições de cada um desses botões.

Quadro 1: Descrições das funções do sistema com as identificações dos botões em Braille.

\begin{tabular}{|c|c|c|}
\hline Função & Descrição & Identificação em Braille \\
\hline Liga botoeira & $\begin{array}{l}\text { Acionamento de uma chave de } \\
\text { liberação/desativação total do } \\
\text { sistema. }\end{array}$ & $\begin{array}{l}: \bullet: \bullet: \\
: \bullet: \bullet: \bullet \bullet \bullet: \bullet: \bullet:\end{array}$ \\
\hline Bi manual & $\begin{array}{l}\text { O sistema de segurança só irá } \\
\text { fazer a liberação do início de ciclo } \\
\text { quando os dois botões forem } \\
\text { acionados ao mesmo tempo. }\end{array}$ & $\begin{array}{l}\bullet \bullet \bullet \bullet \bullet \bullet: \bullet \bullet \bullet \bullet \bullet: \bullet: ~ \\
\bullet \bullet \bullet \bullet \bullet \bullet \bullet: \bullet \bullet: ~\end{array}$ \\
\hline Emergência & $\begin{array}{l}\text { Botão com contato monitorado } \\
\text { ligado em dois circuitos da } \\
\text { máquina, o físico e o lógico. }\end{array}$ & $\bullet \bullet \bullet \bullet: \bullet: \bullet \bullet \bullet \bullet \bullet \bullet \bullet \bullet$ \\
\hline
\end{tabular}




\begin{tabular}{|l|l|l|}
\hline Homing & Volta à posição inicial. Habilitada \\
através de um botão simples, que & estará ligado ao comando lógico \\
da botoeira. & Sistema enviará um sinal de alerta \\
Alerta sonoro & sonoro em casos de parada. \\
\hline Alerta & $\begin{array}{l}\text { Gerado através de um motor } \\
\text { vibratório }\end{array}$ & $\begin{array}{l}\text { instalado na botoeira que será } \\
\text { acionado através do sistema } \\
\text { lógico de controle. }\end{array}$ \\
\hline
\end{tabular}

Fonte: Elaborado pelo autor

O dispositivo de controle de todas as funções será o CLP no qual o mesmo conterá um programa condizente ao funcionamento proposto através do fluxograma de funcionamento (figura 08), onde o CLP irá efetuar todas as lógicas combinatórias para o perfeito funcionamento através de recebimento de sinais em bits de entradas e acionamentos através dos bits de saídas, executando de forma precisa e segura o que será programado no mesmo. 
Figura 08: Fluxograma de funcionamento.

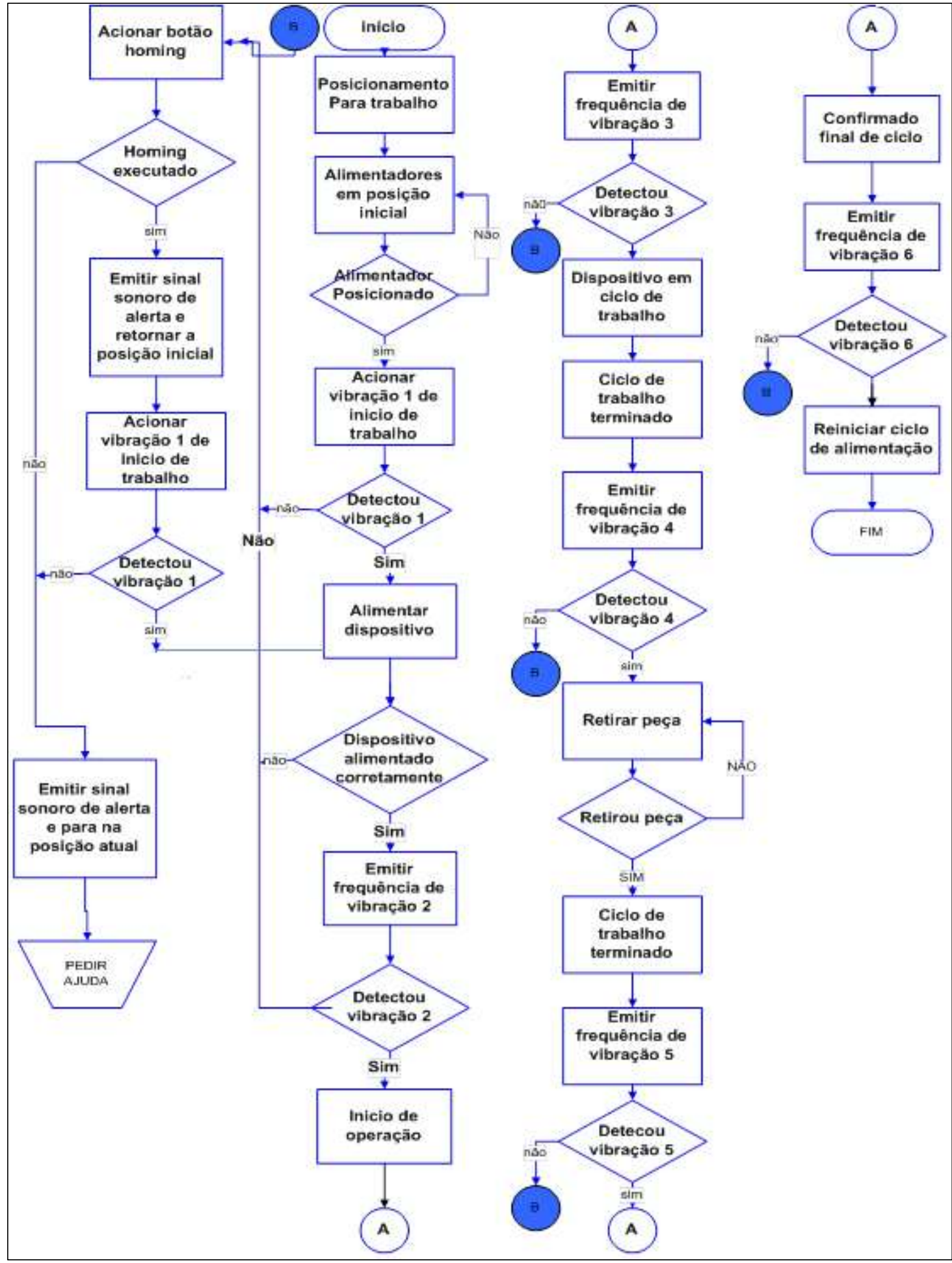

Fonte: Elaborado pelo autor. 
O sistema proposto é composto de dois motores desbalanceados que terá a função principal de gerar vibrações para que possa servir de interface de comunicação entre a máquina e o deficiente visual (figura 09).

Quando este motor é acionado, o eixo, que possui um contrapeso excêntrico, ao realizar sua rotação, faz a botoeira vibrar. A frequência dessa vibração dependerá da função ou alerta que o sistema pretende transmitir ao deficiente visual, isto é, o motor terá uma rotação pré-estabelecida para cada função quantificada conforme equação 12.

Figura 09: Sistema de vibração

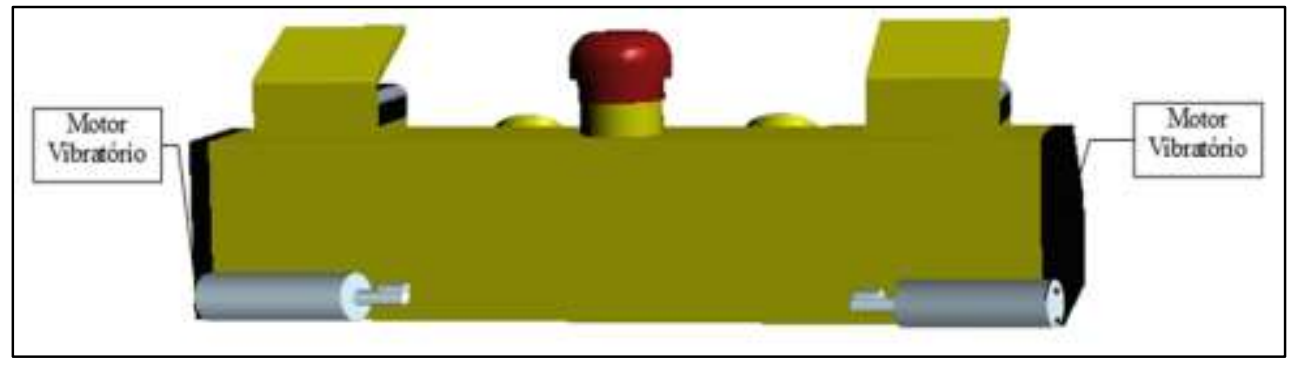

Fonte: Elaborado pelo autor.

\section{Sistemas De Segurança E O Setor De Trabalho}

Este item é de grande importância, pois se trata da definição da segurança dos acionamentos e a integridade física do operador, onde a segurança terá que ser precisa e eficiente a fim de não possibilitar acionamentos sem que o deficiente visual esteja com as duas mãos ao mesmo tempo sobre os botões no momento do acionamento e funcionamento do dispositivo.

Não há normas estabelecidas para a elaboração de tal sistema e dispositivo para a inclusão de um portador de deficiência visual, portanto foi utilizada como base a NR12.

Para obter-se a segurança total do portador de deficiência visual deve-se atentar não apenas para o dispositivo, mas também para a área de trabalho ocupada pelo mesmo, sendo assim será utilizada uma cortina de luz para protegê-lo de eventuais movimentos fora da área de trabalho e que tenha riscos de acidentes. A figura 10 representa a disposição dos dispositivos de segurança.

Através da Norma NBR 9050 foi elaborado um layout do local de trabalho (Figura 11) onde demonstra como se deve incorporar o sistema para o deficiente visual, evidenciando as alterações necessárias para que o deficiente visual possa se locomover de forma segura dentro da linha de produção sendo necessárias algumas alterações na edificação para cumprimento da norma.

Figura 10: Modelo de implantação do sistema de segurança.

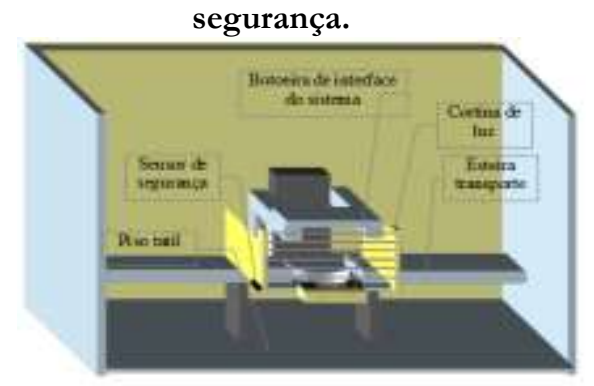

Fonte: Elaborado pelo autor. 
Figura 11: Exemplo de uma adaptação do local de trabalho para deficientes visuais.

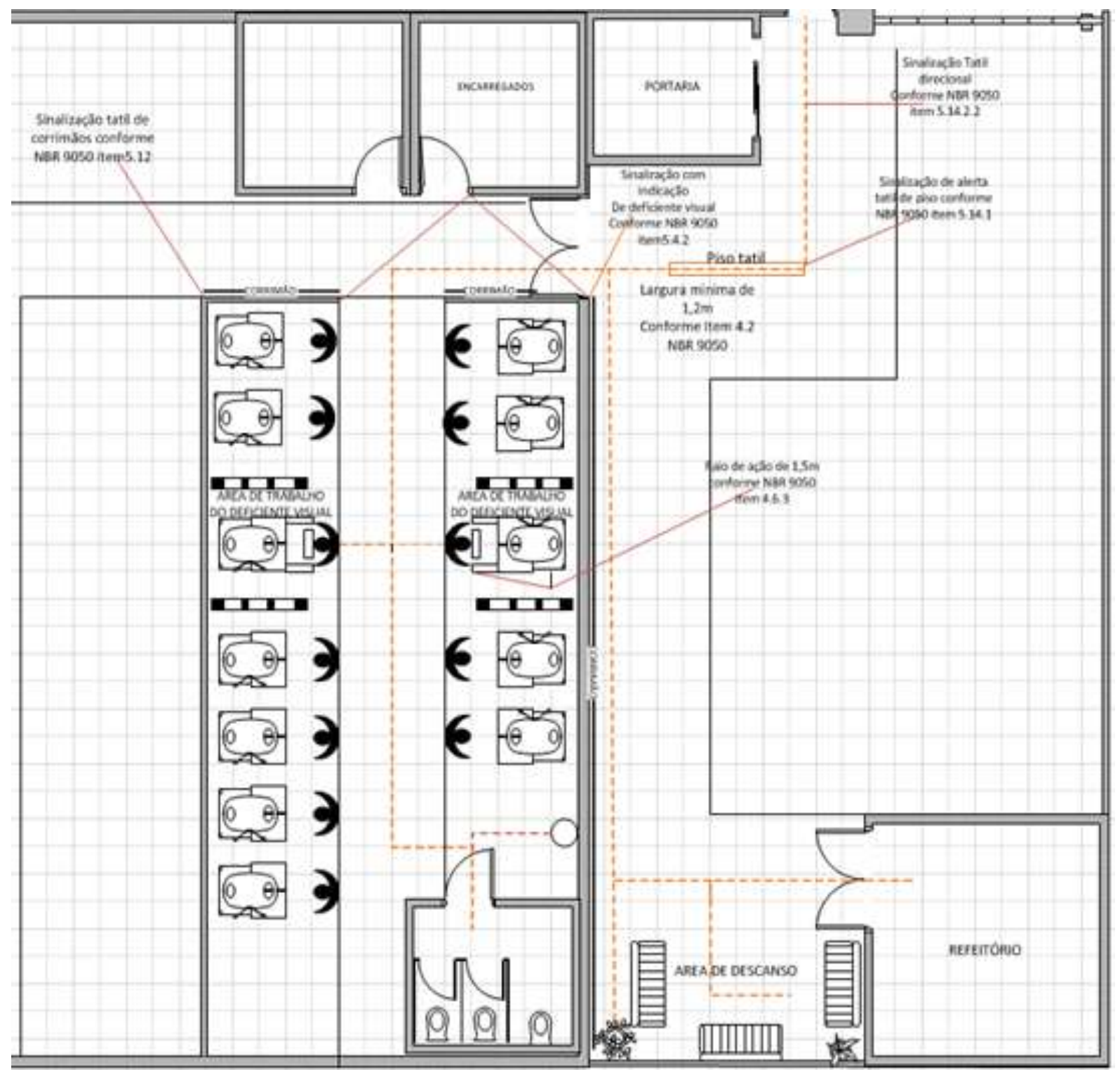

Fonte: Elaborado pelo autor

\section{Conclusão}

O deficiente visual é o mais afetado com a falta de iniciativa de implantar uma política de inclusão na indústria, pois a sua deficiência é contundente no quesito de liberdade ocupacional em um ambiente industrial devido aos perigos que esse possui. O sistema apresentado neste trabalho possibilita a inclusão deste deficiente no ambiente industrial, atentando à sua segurança e cumprimento das normas técnicas dos dispositivos que farão parte deste sistema. A tecnologia utilizada neste projeto é facilmente acessível podendo ser implantada sem custos elevados.

Em todas as pesquisas efetuadas para a elaboração deste trabalho ficou claro que não 
existem normas técnicas para construção, certificação e segurança de dispositivos para deficientes visuais, sendo que no Brasil possuímos apenas a NBR 9050 que normaliza ambiente e edificações. Assim foram feitas adequações no sistema através de normas existentes aplicadas em máquinas e equipamentos usuais, como a NR12 dentre outras citadas neste trabalho, mas vale ressaltar que existe a necessidade de adequação das normas existentes ou a criação de normas específicas para o deficiente visual de forma que estabeleçam regras para introduzir este deficiente no ambiente industrial e que crie respaldo técnico para projetos que visem inserir o deficiente visual, possibilitando assim que sejam elaborados projetos com segurança e confiabilidade.

\section{Referências}

BEER, F.P.; JOHNSTON, R.E; EISENBERG, E.R. Mecânica Vetorial para Engenheiros: Estática. 7 ed. São Paulo: McGraw-Hill, 2006.

CAMPBELL, Larry. Trabalho e cultura: meios de fortalecimento da cidadania e do desenvolvimento humano. Revista Contato Conversas sobre Deficiência Visual - Edição Especial. Ano 5, número 7 - Dezembro de 2001.

CENSO DEMOGRÁFICO 2010. Tabulação Avançada: Resultados Preliminares da Amostra, disponível em
< $\underline{\text { http://www.ibge.gov.br/home/presidencia/n }}$ oticias/08052002tabulacao.shtm>. Acesso em 19/11/2014.

FITZGERALD, A. E.; KINGSLEY, Charles; UMANS, Stephen D. Máquinas elétricas: com introdução à eletrônica de potência. 6 ed. Porto Alegre: Bookman, 2006.

BIRD, Jonh, Circuitos elétricos, teoria e tecnologia. 3 ed. São Paulo: Elsevier, 2009.

GIL, Marta (org). Deficiência Visual. Ministério da Educação. Secretaria de Educação à Distância, n $1 / 2000$.

HIBBELER, Russell C. Dinâmica: Mecânica para Engenharia. 12 ed. São Paulo: Pearson Prentice Hall, 2011.

KOPELVSKI, Maycon M. Teoria de CLP. São Paulo: Instituto Federal, 2010. (Apostila).

MCMILLAN, Robert B., Rotating machinery: practical solutions to unbalance and misalignment. 1 ed. New York, 2004. Maycon Max Kopelvski

MELCONIAN, Sarkis. Elementos de máquinas. 9. ed. São Paulo: Érica, 2008.

NBR NM - 272:2002 - Segurança de máquinas - Proteções - Requisitos gerais para o projeto e construção de proteções fixas e móveis.

NBR NM - 273:2002 - Segurança de máquinas - Dispositivos de intertravamento 
associados a proteções - Princípios para projeto

e seleção.

NEMA - National Electrical Manufacturers

Association (revisão de 18/06/2007).

Disponível em

$<$ https://www.nema.org/Policy/Documents/

GuidanceonEPACT-Tax-Incentive-

Certification-Letters-rev607.pdf > . Acesso em 22/11/2014.

PRUDENTE, Francesco. Automação

Industrial; PLC teorias e aplicações; 2 ed. Rio de Janeiro: LTC, 2011.

RAO, Singiresu. Vibrações mecânicas. 4 ed. São Paulo: Pearson Prentice Hall, 2008.

SÁ, Elizabet D.; CAMPOS, Izilda M.; SILVA, Myriam B. C. Atendimento educacional especializado: Deficiência Visual, 2007. Disponível em: $<\underline{\text { http://portal.mec.gov.br/seesp/arquivos/pdf }}$ Laee dv.pdf>. Acesso em 22/11/2014.

WEG AUTOMAÇÃO. Soluções em Segurança: linha safety. Disponível em: $<\underline{\text { http://ecatalog.weg.net/files/wegnet/WEG- }}$ solucoes-em-seguranca-50029132-catalogoportugues-br.pdf>. Acesso em 18/11/2014. Automatizado Para Inclusão Do Deficiente Visual Na Indústria: Adaptação Do Deficiente Visual Em Uma Célula Produtiva 